\title{
Morbidity in whooping cough and measles
}

\author{
S P CONWAY AND R R PHILLIPS
}

Department of Infectious Diseases, Seacroft Hospital, and University Department of Paediatrics, St James's University Hospital, Leeds

SUMMARY Parents of 99 children who were admitted to hospital with whooping cough or measles, and of 50 children with whooping cough or measles who were nursed at home, were interviewed to determine the extent of morbidity and its effects on the family. Children admitted with whooping cough or measles spent a mean of 12.6 and 5.8 days in hospital, respectively. Time to full recovery was 13.7 and $2 \cdot 1$ weeks, respectively. Over a third of the children who were admitted were emotionally upset during the admission and for several weeks afterwards. Parental anxiety and exhaustion were common. Routine family life was appreciably disturbed. Advice from health care professionals, based on misconceptions of valid contradictions to immunisation, was the main reason for refusing vaccination.

Routine immunisation against whooping cough and measles is recommended for all except a small minority of preschool children. ${ }^{1}$ The vaccines are safe and effective. ${ }^{23}$ Failure to maintain high rates of vaccination results in epidemics ${ }^{245}$ with preventable deaths and serious complications in previously normal children. ${ }^{5-8}$ Even uncomplicated illness can cause substantial morbidity for both patient and family. Public confidence in whooping cough vaccine, eroded by a media campaign, is not reliably supported by the medical profession. ${ }^{9}$ It is probable that the public extrapolates from its misinformation on pertussis vaccine to form erroneous concepts of the dangers of, and contraindications to, measles vaccine. ${ }^{1011}$ In 1985 the percentage of eligible children in England vaccinated before 3 years of age was $85 \%$ for diphtheria, tetanus, and polio but only $65 \%$ for pertussis and $68 \%$ for measles. The World Health Organisation's target is primary immunisation in $90 \%$ of all European children less than 2 years of age by 1990 .

The aim of this study was to identify the morbidity associated with whooping cough and measles, the emotional and financial hardships that they cause within the family, and the areas where communication between health care professionals and the community has broken down.

\section{Patients and methods}

All children with whooping cough or measles admitted to Seacroft Hospital (which offers a service covering several districts to children with infectious diseases) from February 1986 to June 1987 were identified and examined by one of us. Mothers were asked at discharge if they would agree to be interviewed within the next six months about both their experience of the illness and their views on the childhood immunisation programme. Parents of 99 children were interviewed at home with a semistructured questionnaire. This had previously been assessed by the Leeds Health Education Service, firstly with a sample of people who understood only straight forward English, and secondly with teachers of English as a second language. The questions were designed to provide information on the immunisation state of the child, parental knowledge about the illnesses and the vaccines, reasons for failure to take up the immunisation, and the financial, emotional, and social impact of these preventable diseases on the family. Mothers of children notified to the Leeds medical officer of environmental health as having whooping cough or measles, and who were nursed at home, were also interviewed. All interviewees were selected randomly to provide a mix of social class. The study was approved by the hospital ethics committee.

\section{Results}

Seventy two children admitted with whooping cough, 27 admitted with measles, and 50 notified as suffering whooping cough $(n=25)$ or measles $(n=25)$ but not referred to hospital, were entered 
into the study. Overall, eight children (one admitted) were from social class I families, 27 (12 admitted) from class II, 53 (33 admitted) from class III, 15 (13 admitted) from class IV and 46 (40 admitted) from class $\mathrm{V}$. Both interviewers obtained similar results.

The consequences of measles or whooping cough for the family and child are summarised in tables 1 and 2 . The primary reasons for refusal of vaccination by parents of children eligible for immunisation are summarised in table 3 . Only six of 97 cases of whooping cough had received pertussis immunisa- tions $(6 \%)$, whereas $26(50 \%)$ of 52 children with measles had received measles immunisation. This included $19(76 \%)$ of the 25 cases that were notified but treated at home.

The mothers of 10 children with whooping cough $(7 \%)$, and 52 children with measles $(35 \%)$ did not consider the illnesses to be serious. Ninety four $(63 \%)$ felt that they had not received sufficient information about childhood immunisation. Further information requested was consistently: What is the disease? How do the side effects of the vaccine

Table 1 Consequences of measles and whooping cough for the child and family

\begin{tabular}{ll}
\hline & $\begin{array}{l}\text { Whooping cough } \\
(n=97)\end{array}$ \\
\hline No $(\%)$ of parents feeling exhaustion and & $69(71)$ \\
having disturbed nights for up to 3 months & $43(44)$ \\
No $(\%)$ of parents with severe anxiety & $28(29)$ \\
No $(\%)$ of parents who feared that their child would die & $12 \cdot 6(3-35)$ \\
Mean hospital stay and range (days) & $13 \cdot 7(1$ weck-6 months) \\
Mean length (weeks) of illness (range) & $13 \cdot 8(3-16)$ \\
\hline
\end{tabular}

Table 2 General consequences of admission to hospital for the child and family $(n=99)$

No $(\%)$ of parents who described their child as:

Upset in hospital, clinging

Crying or demanding after discharge

37 (37)

38 (38)

49 (49)

Mean (range) time spent travelling to and from hospital each day by mother or father (hours)

Median (range) cost/day (f) spent in travel to and from hospital

No $(\%)$ of families of admitted children with their own car

Median (range) amount $(f)$ spent on extra toys and sweets $(n=28)$

Median (range) number of parental working days lost as a result of child's illness $(n=38)$

Table 3 Most common reasons for not accepting vaccination

\begin{tabular}{|c|c|c|}
\hline & $\begin{array}{l}\text { Pertussis } \\
\text { No }(\%)\end{array}$ & $\begin{array}{l}\text { Measeles } \\
\text { No }(\%)\end{array}$ \\
\hline Fear of side effects & $35 \quad(37)$ & 0 \\
\hline \multicolumn{3}{|l|}{ Family history of: } \\
\hline Fits & $32 \quad(34)$ & $7 \quad(18)$ \\
\hline Mental retardation & $3 \quad(3)$ & $1 \quad(3)$ \\
\hline Atopy & $10 \quad(11)$ & 7 (17) \\
\hline Fits in the child & $3 \quad(3)$ & 0 \\
\hline Parental apathy or disbelief in the value of immunisation & (4) & $9 \quad(23)$ \\
\hline Child always had 'colds' & (7) & (23) \\
\hline Spina bifida & (1) & 0 \\
\hline Previously had target illness & 0 & (8) \\
\hline Concurrent antibiotic treatment & 0 & (3) \\
\hline No recall card received & 0 & (5) \\
\hline Total & $94(100)$ & $39(100)$ \\
\hline
\end{tabular}


compare with the complications of the disease? How effective is the vaccine? Sixty parents $(40 \%)$ had been influenced by adverse publicity. One hundred and forty three $(96 \%)$ agreed with the principle of childhood immunisation.

\section{Discussion}

The severity of measles and whooping cough, though well documented, ${ }^{5-8}$ is not consistently appreciated by either health care professionals ${ }^{12}$ or parents. ${ }^{13}$ Our study illustrates the extended family morbidity resulting from these illnesses (especially for pertussis) with parental exhaustion and severe anxiety being common. Considerable time and money are spent in visiting, working days are lost, and with $40 \%$ of parents sleeping in hospital with their children, social disruption at home is inevitable. These effects may be felt within the family for weeks or months. Thirteen $(37 \%)$ of 35 social classes I and II children were admitted, compared with $53(87 \%)$ of 61 from social classes IV and V. These socially disadvantaged families are perhaps least able to cope with the emotional and financial stress of having a child in hospital, and a child who may then need a long period of convalescence at home.

Acceptance of immunisation reflects belief in the efficacy and safety of the vaccine and realisation of the seriousness of the disease. ${ }^{9}$ Misconceptions about the severity of childhood illness will gain credence from casual misdiagnosis. Three children had been diagnosed as having measles when less than 1 year of age, and were not subsequently given measles vaccine. A high proportion $(68 \%)$ of such infants are seronegative to measles antigen. ${ }^{14}$ Seventy six per cent of the 25 children with measles who were nursed at home had received measles vaccine. Many parents described a short lived feverish illness with a rash, but without conjunctivitis or cough. Misdiagnosis of other, less severe, viral infections as measles will perpetuate the myth that measles is a trivial illness. Diagnosis of measles in immunised children will erode faith in the efficacy of the vaccine. We suggest that when measles is diagnosed in children under 1 year old or who have previously been immunised, the diagnosis should be confirmed by serology.

The results of this study illustrate the many reasons given for non-immunisation, despite most parents' belief in the general principle of childhood immunisation. All our information was received from interviews with parents only, and it must be considered possible that their memories of contact with health care personnel, and of the advice offered to them, may be clouded by their own attitudes to immunisation, and feelings of guilt after their child had contracted a serious illness. None the less, the results of this study suggest that it is the health care professionals who-through advice based on misconceptions of the valid contraindications to immunisation-fail to protect children against these preventable infectious diseases. Our results show that the same misconceptions are being perpetuated that were recorded in earlier studies. ${ }^{910}$ Nor is the profession consistent in the information it delivers to parents ${ }^{15-17}$; there are clear disparities in general practitioners' and health visitors' convictions about the need for whooping cough and measles vaccine compared with those for diphtheria, polio, and tetanus. ${ }^{12} 18$

Local $^{19}$ and national ${ }^{20}$ studies have shown that professional commitment, publicity campaigns, and involvement of parents can raise the vaccination rate to the targeted $90 \%$ for primary immunisation of all European children less than 2 years of age. We have shown that there is extended morbidity for children and families during and after measles or pertussis infection. The target immunisation rate must be met.

We thank Leeds University for its grant, Mrs V Rowell and Dr M Schweiger for their advice, and Dr J Stevenson and Dr H Pullen for allowing us to include their patients.

\section{References}

1 Department of Health and Social Security. Immunisation against infectious disease. London: HMSO, 1988.

2 Begg NT. Childhood vaccine-preventable disease. Public Health Laboratory Service Microbiology Digest 1987;4:38-40.

3 Block AB, Orenstein WA, Stetles HC, et al. Health impact of measles vaccination in the United States. Pediatrics 1985;76: 524-32.

4 MacKenzie AG. Children not immunised for measles. $\mathrm{Br}$ Med J 1985;290:1902.

5 Swansea Research Unit of the Royal College of General Practitioners. Effect of a low pertussis vaccine uptake on a largi community. Br Med J 1981;282:23-6.

6 Miller CL. Severity of notified measles. Br Med J 1978;i:1253.

7 Miller CL. Death from measles in England and Wales 1970-83. Br Med J 1985;290:443-4.

${ }^{8}$ Nicoll A, Gardner A. Whooping cough and unrecognised postperinatal mortality. Arch Dis Child 1988;63:41-7.

9 Stevens D, Baker R, Hands S. Failure to vaccinate against whooping cough. Arch Dis Child 1986;61:382-7.

${ }_{10}$ Nicoll A. Contra-indications to whooping cough immunisationmyths or realities. Lancet $1985 ; \mathrm{i}: 679-81$.

1 Adjaye N. Measles immunisation. Some factors affecting nonacceptance of vaccine. Public Health 1981;95:185-8.

12 Wilkinson P, Tylden-Patterson L, Gould J. Professional attitudes towards vaccination and immunisation within the Leeds Area Health Authority. Public Health 1979;93:11-5.

${ }^{13}$ Blair S, Shave N, McKay J. Measles matters, but do parents know. Br Med J 1985;290:623-4.

14 Adjaye N, Azad A, Foster M, Marshall WC, Dunn H. Measles serology in children with a history of measles in early life. $\mathrm{Br}$ Med J 1983;286:1478. 
${ }^{15}$ Hull D. Interpretation of the contra-indications to whooping cough vaccination. Br Med J 1981;283:1231-3.

16 Wilkinson JR. Measles immunisation-contra-indications as interpreted by health visitors and clinic nurses. Public Health 1985;99:198-200.

17 Lakhani ADH, Morris RW, Morgan M, Dale C, Vaile MSB. Measles immunisation: feasibility of a $90 \%$ target uptake. Arch Dis Child 1987;62:1209-4.

${ }^{18}$ Clarke SJ. Whooping cough vaccination: some reasons for noncompletion. J Adv Nurs 1980;5:313-9.
${ }^{19}$ Colver AF. Immunisation strategy. Lancet 1987;ii:457.

${ }^{20}$ Noah ND. Immunisation before school entry: should there be a law? Br Med J 1987;294:1270-1.

Correspondence to Dr SP Conway, Seacroft Hospital, York Road, Leeds LS14 6UH.

Accepted 5 June 1989 